\title{
Rit GTPase Signaling Promotes Immature Hippocampal Neuronal Survival
}

\author{
Weikang Cai, ${ }^{1}$ Shaun W. Carlson, ${ }^{2}$ Jennifer M. Brelsfoard, ${ }^{2}$ Catherine E. Mannon, ${ }^{1}$ Carole L. Moncman, ${ }^{1}$ \\ Kathryn E. Saatman, ${ }^{2}$ and Douglas A. Andres ${ }^{1}$ \\ ${ }^{1}$ Department of Molecular and Cellular Biochemistry, and ${ }^{2}$ Spinal Cord and Brain Injury Research Center and Department of Physiology, University of \\ Kentucky College of Medicine, Lexington, Kentucky 40536-0509
}

The molecular mechanisms governing the spontaneous recovery seen following brain injury remain elusive, but recent studies indicate that injury-induced stimulation of hippocampal neurogenesis contributes to the repair process. The therapeutic potential of endogenous neurogenesis is tempered by the demonstration that traumatic brain injury (TBI) results in the selective death of adult-born immature neurons, compromising the cell population poised to compensate for trauma-induced neuronal loss. Here, we identify the Ras-related GTPase, Rit, as a critical player in the survival of immature hippocampal neurons following brain injury. While Rit knock-out (Rit ${ }^{-1-}$ ) did not alter hippocampal development, hippocampal neural cultures derived from $\mathrm{Rit}^{-1-}$ mice display increased cell death and blunted MAPK cascade activation in response to oxidative stress, without affecting BDNF-dependent signaling. When compared with wild-type hippocampal cultures, Rit loss rendered immature $\left(\mathrm{Dcx}^{+}\right)$neurons susceptible to oxidative damage, without altering the survival of neural progenitor $\left(\right.$ Nestin $^{+}$) cells. Oxidative stress is a major contributor to neuronal cell death following brain injury. Consistent with the enhanced vulnerability of cultured $\mathrm{Rit}^{-1-}$ immature neurons, Rit $^{-1-}$ mice exhibited a significantly greater loss of adult-born immature neurons within the dentate gyrus after TBI. In addition, post-TBI neuronal remodeling was blunted. Together, these data identify a new and unexpected role for Rit in injury-induced neurogenesis, functioning as a selective survival mechanism for immature hippocampal neurons within the subgranular zone of the dentate gyrus following TBI.

\section{Introduction}

Hippocampal neurogenesis results in the generation of new neurons throughout life (Zhao et al., 2008). In this process, neural stem cells proliferate and differentiate into committed neural progenitor cells, which in turn develop into immature neurons. As they continue to mature, these neurons integrate into the existing circuitry (Ming and Song, 2011), playing a critical role in maintaining brain homeostasis. A major fraction of adult-born neurons undergo apoptosis at early stages of development, and neural birth, survival, and differentiation are heavily influenced by physiological and pathological regulation (Zhao et al., 2008; Ming and Song, 2011). Although much has been learned about neurogenesis, the regulatory mechanisms controlling proliferation, differentiation, and survival of adult-born neurons remain incompletely characterized.

Traumatic brain injury (TBI) is a leading cause of death and chronic disability (Bruns and Hauser, 2003), both because of the

Received Jan. 25, 2012; revised May 6, 2012; accepted June 2, 2012.

Author contributions: W.C., S.W.C., K.E.S., and D.A.A. designed research; W.C., S.W.C., J.M.B., C.E.M., and C.L.M. performed research; W.C., K.E.S., and D.A.A. analyzed data; W.C., K.E.S., and D.A.A. wrote the paper.

This work was supported by Public Health Service Grants NS045103 (D.A.A.), NS058484 (K.E.S.), and NS072302 (K.E.S.) from the National Institute of Neurological Disorders and Stroke, Kentucky Spinal Cord and Head Injury Research Trust Grant 7-20 (K.E.S.), and National (enter for Research Resources Grant 2P20 RR020171 (D.A.A.). We thank Drs. G.-X. Shi, M. Gentry, and P. Lein for helpful discussions. This manuscript is solely the responsibility of the authors and does not necessarily represent the official views of the NIH or the NCRR.

Correspondence should be addressed to Dr. Douglas A. Andres, BBSRB 179, University of Kentucky College of Medicine, 741 South Limestone Street, Lexington, KY 40536-0509. E-mail: dandres@uky.edu.

DOI:10.1523/JNEUROSCI.0375-12.2012

Copyright $\odot 2012$ the authors $\quad 0270-6474 / 12 / 329887-11 \$ 15.00 / 0$ physical damage resulting from the primary insult but also as the result of secondary damage triggered by diverse stimuli, including oxidative stress (Povlishock and Katz, 2005). The hippocampus is particularly vulnerable to these secondary injury cascades (Levin, 1998), with a significant number of newborn immature neurons undergoing apoptosis early after TBI, initially setting back neurogenesis within the dentate gyrus (Rola et al., 2006; Gao et al., 2008). While the mechanisms underlying spontaneous recovery from brain injury remain unclear, it is well established that a variety of brain insults stimulate a period of increased hippocampal neurogenesis (Weinstein et al., 1996; Gould and Tanapat, 1997; Magavi et al., 2000; Jin et al., 2001; Kernie et al., 2001). Importantly, adult-born neurons generated in the damaged brain may replenish lost neurons (Magavi et al., 2000), and stimulation of neurogenesis has been correlated with improved neurological recovery (Liu et al., 2007; Schäbitz et al., 2007; Meng et al., 2011). Disruption of this program impairs the innate regenerative process and has been linked to cognitive dysfunction in mouse models (Blaiss et al., 2011). Presumably, specific cellular signaling pathways regulate both basal and injury-induced neurogenesis.

The Ras-related GTPase, Rit, is expressed in a majority of adult and embryonic tissues, including a variety of primary neurons and the developing brain (Lee et al., 1996; Wes et al., 1996; Spencer et al., 2002b; Lein et al., 2007). Despite its widespread occurrence in the nervous system, its cellular function(s) in neurons remain incompletely characterized. To understand the function of Rit in the mammalian CNS, we examined Rit knock- 
out $\left(\right.$ Rit $^{-/-}$) mice. Rit deficiency renders cultured immature hippocampal neurons susceptible to apoptosis and results in a selective disruption of MAPK and Akt signaling pathways in response to oxidative stress. Because reactive oxygen species (ROS)-mediated damage is a major trigger of neuronal apoptosis following brain injury (Lewén et al., 2000) and newborn neurons appear especially vulnerable to TBI, we examined the fate of adult-born hippocampal neurons in $\mathrm{Rit}^{-1-}$ mice after TBI. Loss of Rit resulted in increased neurodegeneration in the dentate gyrus and fewer surviving newborn neurons, supporting a role for Rit in the survival of adult-born hippocampal neurons following traumatic injury.

\section{Materials and Methods}

Animals. The generation of $\mathrm{Rit}^{-/-}$mice and genotyping strategy were as described previously (Cai et al., 2011). Mice were housed in a pathogenfree facility and handled in accordance with standard use protocols, animal welfare regulations of the University of Kentucky, and the NIH Guide for the Care and Use of Laboratory Animals.

Reagents. Hydrogen peroxide $\left(\mathrm{H}_{2} \mathrm{O}_{2}\right)$ (Sigma-Aldrich); BDNF (R\&D Systems); Fluoro-Jade C (FJC) (Millipore); 5-bromo-2-deoxyuridine (BrdU) (Thermo Fisher Scientific); p38 MAPK kinase specific inhibitors 4-[4-(4fluorophenyl)-2-(4-methylsulfinylphenyl)- $1 H$-imidazol-5-yl]pyridine (SB203580) (Tocris); and antibodies against $\beta$-actin (Sigma-Aldrich), phospho-p38, p38, phospho-Akt $\left(\operatorname{Ser}^{473}\right)$, Akt (Cell Signaling), Doublecortin (Dcx) (rabbit) (Abcam), neuronal nuclei (NeuN), Dcx (guinea pig) (Millipore), Nestin (Covance), microtubule-associated protein 2 (MAP2) (clone AP20; Sigma-Aldrich), FITC anti-mouse IgG, Cy3 anti-rabbit IgG, Cy3 antirat IgG, Cy5 anti-mouse IgG, FITC anti-rabbit IgG (Jackson ImmunoResearch), and FITC anti-guinea pig IgG (Invitrogen) were purchased.

Primary hippocampal neuron culture. Primary cultures of hippocampal neurons were prepared from C57BL/6 wild-type (WT) and Rit ${ }^{-1-}$ pups within $12 \mathrm{~h}$ of birth (P0). Hippocampi were surgically dissected, dissociated by treatment for $30 \mathrm{~min}$ at $37^{\circ} \mathrm{C}$ in a solution of DMEM (Invitrogen) supplemented with $4 \mathrm{mg} / \mathrm{ml}$ papain (Sigma-Aldrich) and $0.0025 \mathrm{mg} / \mathrm{ml}$ DNase I (Sigma-Aldrich), subjected to gentle trituration in DMEM plus $10 \%$ FBS, and plated on poly-D-lysine $(0.1 \mathrm{mg} / \mathrm{ml}$ in $5 \mathrm{~mm}$ Tris, $\mathrm{pH}$ 8.0)-coated tissue culture dishes or coverslips. After a $4 \mathrm{~h}$ incubation at $37^{\circ} \mathrm{C}$, the medium was replaced with serum-free Neurobasal medium (Invitrogen) supplemented with $0.5 \mathrm{~mm}$ glutamine, B27 (Invitrogen), and $100 \mu \mathrm{g} / \mathrm{ml}$ streptomycin and $100 \mathrm{U} / \mathrm{ml}$ penicillin (Invitrogen) (complete Neurobasal medium). Cells were incubated in a humidified incubator at $37^{\circ} \mathrm{C}$ and $5 \% \mathrm{CO}_{2}$. After $3 \mathrm{~d}$ in vitro (DIV3), one-half of the growth medium was removed and replaced with fresh complete Neurobasal media supplemented with the antimitotic cytosine- $\beta$-D-arabinoside ( $5 \mu \mathrm{M}$; SigmaAldrich) to eliminate non-neuronal cells ( $<5 \%$ of total cells stained with GFAP). At DIV7, the cells were refed with complete Neurobasal media. All experiments were performed at DIV8 unless otherwise noted.

Immunostaining and cell death assay. Hippocampal neural cultures (DIV8) were left untreated or exposed to $\mathrm{H}_{2} \mathrm{O}_{2}$ at the indicated concentration and duration. To block $\mathrm{p} 38$ activity, neuron cultures were preincubated with $10 \mu \mathrm{M}$ SB203580 for $30 \mathrm{~min}$ before $\mathrm{H}_{2} \mathrm{O}_{2}$ exposure. Cells were fixed with fresh 4\% PFA for $15 \mathrm{~min}$. Briefly, cells were washed three times with PBS and permeabilized by $5 \mathrm{~min}$ incubation in $1 \times$ PBS containing $0.1 \%$ Triton $\mathrm{X}-100$ at room temperature (RT). Cultures were blocked for $1 \mathrm{~h}$ at $\mathrm{RT}$ in $5 \%$ normal goat serum (NGS), incubated overnight at $4^{\circ} \mathrm{C}$ with the indicated primary antibodies [MAP-2 (1:1000), Dcx (rabbit, 1:1000; guinea pig, $1: 10,000)$, NeuN (1:1000), or Nestin (1:500)] diluted in $1 \times$ PBS containing $5 \%$ NGS (buffer B). Cells were washed with $1 \times$ PBS (three times) and incubated $1 \mathrm{~h}$ at RT with the appropriate secondary antibodies (1:1000) diluted in buffer B. Cells were then rinsed with $1 \times$ PBS (three times) and coverslipped with SlowFade Gold mounting media with DAPI (Invitrogen). Immature neurons and neural stem cells were identified by Dcx/Nestin staining and DAPI used to identify apoptotic neurons with condensed nuclei using a Zeiss Axiovert 200M fluorescence microscope (>300 cells/treatment). Representative images were captured with a Nikon CKX31 A1 confocal microscope, using a $20 \times$ objective, and cells were analyzed from 10 to 20 randomly selected areas.
Immunoblotting. Wild-type and $\mathrm{Rit}^{-1-}$ hippocampal neurons (DIV8) were briefly starved in serum-free DMEM for $40 \mathrm{~min}$ before the $\mathrm{H}_{2} \mathrm{O}_{2}(40$ $\mu \mathrm{M} ; 15 \mathrm{~min})$ or BDNF $(50 \mathrm{ng} / \mathrm{ml} ; 10 \mathrm{~min})$ stimulation. Whole-cell lysates were prepared using kinase lysis buffer [20 mM HEPES, pH 7.4, $150 \mathrm{~mm}$ $\mathrm{NaCl}, 50 \mathrm{~mm} \mathrm{KF}, 50 \mathrm{~mm} \beta$-glycerolphosphate, 2 mм EGTA, pH 8.0, $1 \mathrm{~mm}$ $\mathrm{Na}_{3} \mathrm{VO}_{4}, 1 \%$ Triton $\mathrm{X}-100,10 \%$ glycerol, and $1 \times$ protease inhibitor cocktail set I (Calbiochem)]. Protein phosphorylation was determined by immunoblotting with the appropriate phosphospecific antibodies and band intensity quantified by NIH ImageJ as described previously (Cai et al., 2011; Shi et al., 2011).

Controlled cortical impact. The surgical procedures were performed as described previously (Pleasant et al., 2011). Male mice were subjected to controlled cortical impact (CCI) injury at a $1.0 \mathrm{~mm}$ impact depth and a nominal velocity of $3.5 \mathrm{~m} / \mathrm{s}$ by the CCI impactor device (TBI-0310 Impactor; Precision Systems and Instrumentation).

$B r d U$ administration. Eleven-week-old male mice were intraperitoneally injected with $\mathrm{BrdU}(50 \mathrm{mg} / \mathrm{kg}$ in $0.9 \%$ saline) daily for 1 week. After the final injection, mice were housed for another $2 \mathrm{~d}$ before CCI to deplete any remaining unincorporated BrdU and insure that hippocampal BrdU ${ }^{+}$cells were immature neurons $\left(\mathrm{Dcx}^{+}\right)$.

Tissue preparation and histology. Mice were anesthetized with sodium pentobarbital $(65 \mathrm{mg} / \mathrm{kg}$, i.p.), transcardially perfused with heparinized saline followed by $10 \%$ buffered formalin, and decapitated (Pleasant et al., 2011). After $24 \mathrm{~h}$ of postfixation in $10 \%$ buffered formalin, brains were removed from the skull, postfixed for an additional $24 \mathrm{~h}$, cryoprotected in $30 \%$ sucrose, and quickly frozen in $-30^{\circ} \mathrm{C}$ isopentane. Serial coronal $40 \mu \mathrm{m}$ sections were cut using a freezing sliding microtome (Dolby-Jamison). Every tenth section (400 $\mu \mathrm{m}$ intervals between sections) was mounted onto gelatin-coated slides, stained with cresyl violet, and coverslipped with Vectashield. For calculation of contusion volume, the neocortical area containing surviving neurons was quantified as described previously (Pleasant et al., 2011). Representative images for Nissl staining were taken using an Olympus AX80 light microscope.

Fluoro-Jade C staining. Serial brain sections taken at $400 \mu \mathrm{m}$ intervals were dried on slides at $40-45^{\circ} \mathrm{C}$ for $15 \mathrm{~min}$ followed by overnight air drying. On the second day, sections were sequentially rinsed in $80 \%(\mathrm{v} / \mathrm{v})$ ethanol containing $1 \%(\mathrm{w} / \mathrm{v}) \mathrm{NaOH}, 70 \%(\mathrm{v} / \mathrm{v})$ ethanol, and $\mathrm{dH}_{2} \mathrm{O}$ before incubation in $0.06 \%(\mathrm{w} / \mathrm{v})$ potassium permanganate for $10 \mathrm{~min}$ in the dark and five subsequent $\mathrm{dH}_{2} \mathrm{O}$ washes. The sections were then incubated in $0.0001 \%$ Fluoro-Jade C solution (resuspended in $0.1 \%$ acetic acid) in the dark for 10 min followed by extensive washing with $\mathrm{dH}_{2} \mathrm{O}$. DAPI was used as a counterstaining agent to label cell nuclei. The slides were dried, cleared in xylenes, and coverslipped with Cytoseal. To quantify FJC-positive cells, three sections (preepicenter, epicenter, and postepicenter; $400 \mu \mathrm{m}$ intervals) from each animal were counted. Representative images were captured using a Nikon CKX31 Al confocal microscope ( $20 \times$ objective).

Immunofluorescence analysis. Brain sections were placed in 24-well plates and washed three times in $1 \times$ PBS for $5 \mathrm{~min}$. The sections were then permeabilized and blocked by the addition of $5 \%$ NGS and $0.1 \%$ Triton X-100 in $1 \times$ PBS (buffer C) and agitated for $30 \mathrm{~min}$ at RT. For BrdU detection, sections were incubated in $2 \mathrm{~N} \mathrm{HCl}$ for $30 \mathrm{~min}$ at $\mathrm{RT}$, followed by the application of neutralizing buffer $(0.1 \mathrm{M}$ borate buffer, $\mathrm{pH}$ 8.0) (10 min), and washed with $1 \times$ PBS (three times), before permeabilization. To improve overall image quality, one overnight PBS wash was included. After blocking, primary antibodies diluted in buffer B were added with gentle rocking overnight at $4^{\circ} \mathrm{C}$. Antibody dilutions were as follows: rabbit anti-Dcx, 1:500; guinea pig anti-Dcx, 1:5000; mouse anti-NeuN, 1:1000; rat anti-BrdU, 1:500. On the following day, sections were washed with $1 \times$ PBS (four times) and secondary antibody (goat anti-rabbit IgG FITC, 1:1000; goat anti-guinea pig IgG Alexa Fluor 488, 1:1000; goat anti-mouse IgG Cy5, 1:1000; goat anti-rat IgG Cy3, $1: 1000)$ diluted in buffer $C$ was applied. Sections were then washed with $1 \times$ PBS (four times) and coverslipped with SlowFade Gold containing DAPI.

To quantify fluorescently labeled cells in the dentate gyrus, three sections (preepicenter, epicenter, postepicenter; $400 \mu \mathrm{m}$ intervals) were counted using a Nikon Eclipse E600 fluorescence microscope $(40 \times \mathrm{ob}$ jective). The focal plane was moved throughout the $z$-axis to capture each 
A

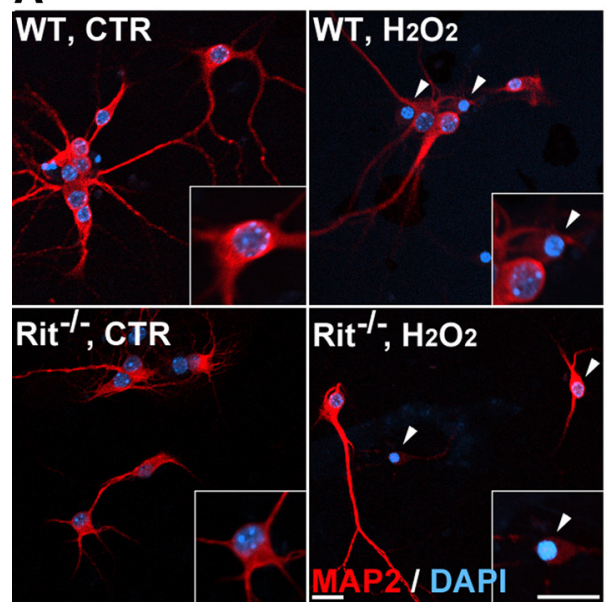

B

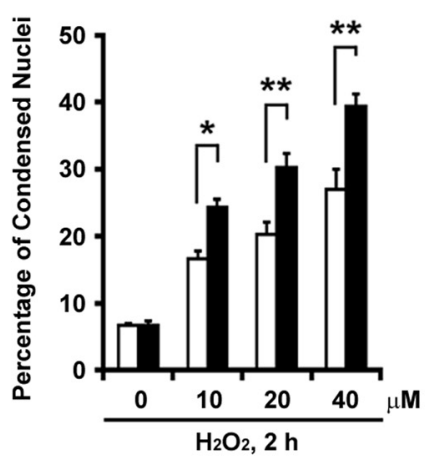

C

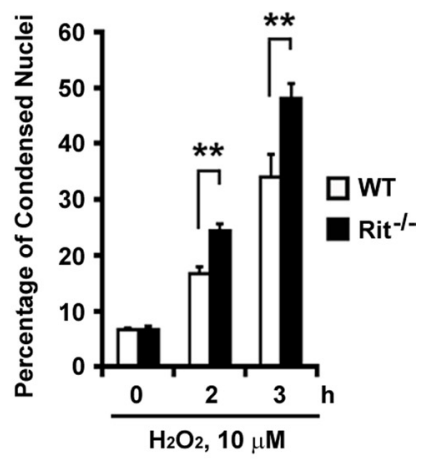

Figure 1. Loss of endogenous Rit sensitizes primary hippocampal neurons to hydrogen peroxide. $A$, WT and Rit $^{-1-}$ hippocampal neural cultures (DIV8) were left untreated [control (CTR)] or subjected to $\mathrm{H}_{2} \mathrm{O}_{2}$ exposure ( $40 \mu \mathrm{m} ; 2 \mathrm{~h}$ ). Fixed cells were immunostained with MAP2 antibody (red) to label cell bodies and dendrites, and nuclei were visualized by DAPI stain (blue). The insets are at higher magnification. The arrowheads indicate neurons with condensed nuclei. Scale bar, $20 \mu \mathrm{m}$. B, C, The percentage of WT (open bar) and Rit ${ }^{-1-}$ (filled bar) neurons with condensed/ fragmented nuclei are presented as mean \pm SEM as a function of dose $(\boldsymbol{B})$ or duration of exposure $(\boldsymbol{C})$ to hydrogen peroxide (two-way ANOVA followed by Newman-Keuls post hoc test: ${ }^{*} p<0.05$, $\left.{ }^{* *} p<0.01, n \geq 3\right)$.

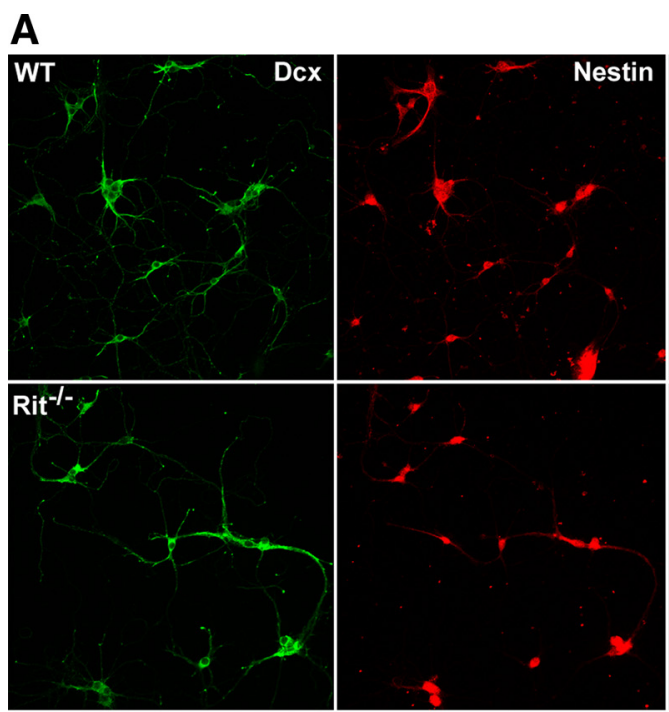

B

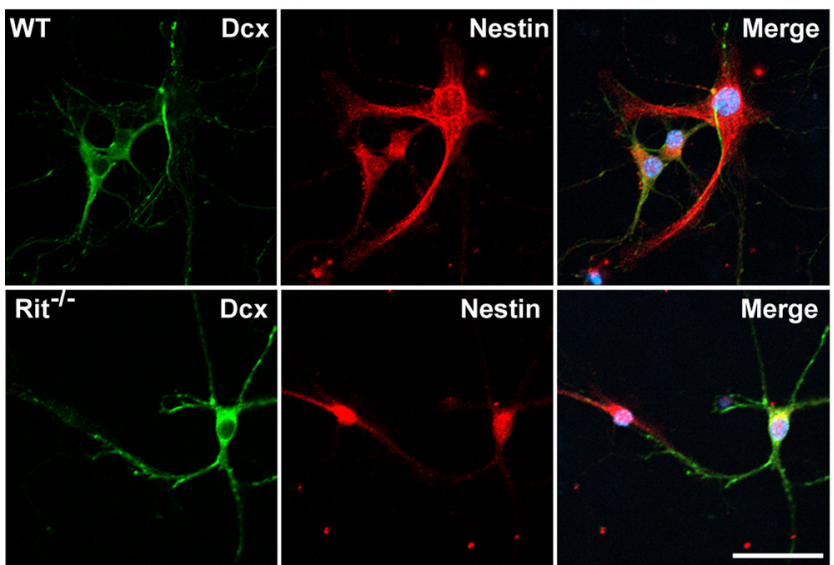

C
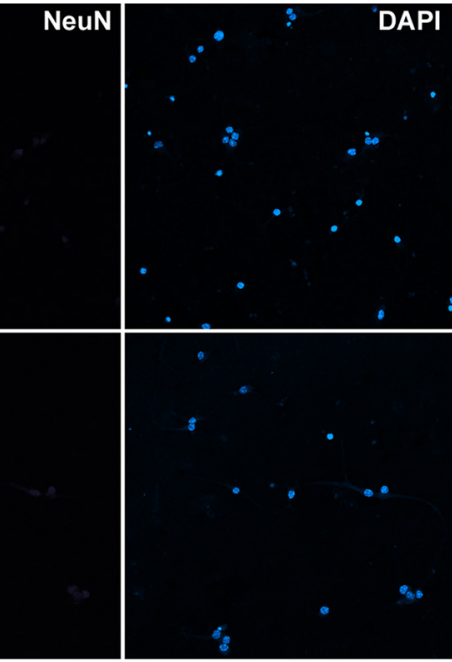

DAPI
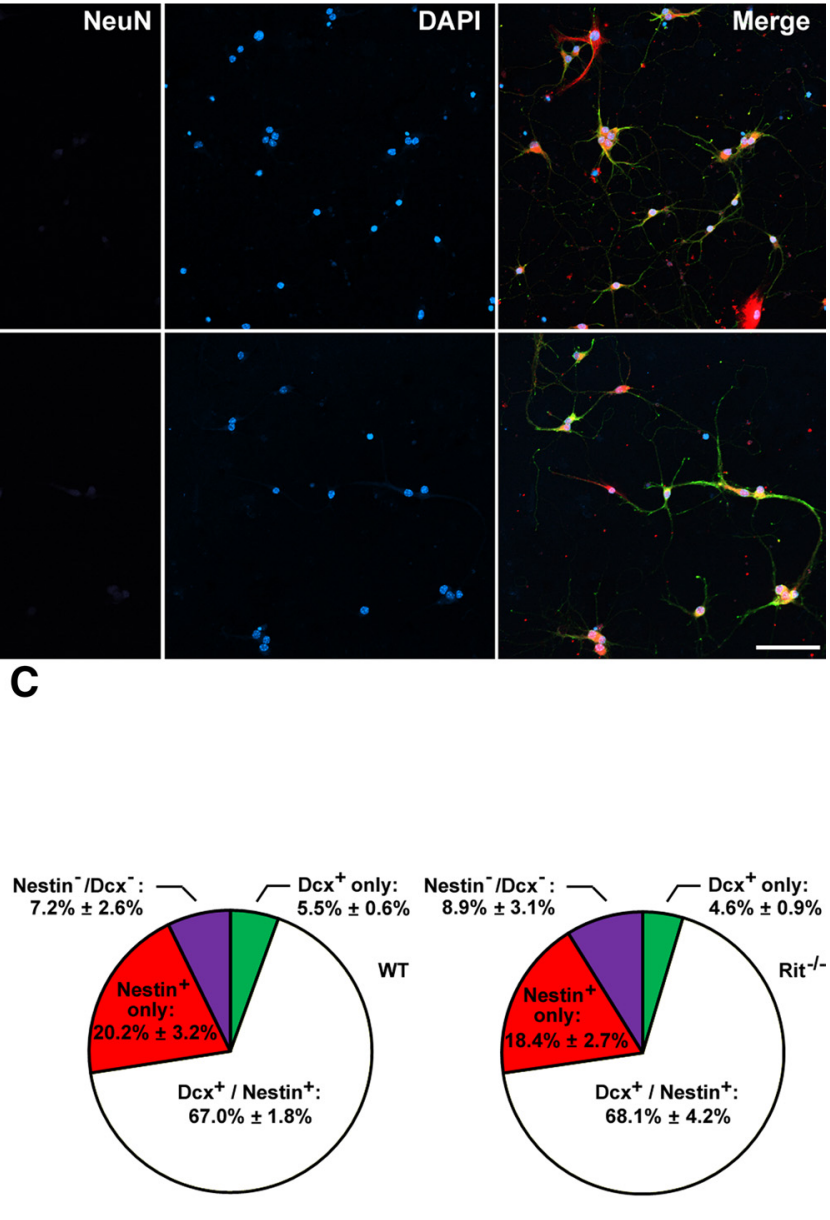

Figure 2. Cellular composition of hippocampal cultures. $A$, WT and Rit ${ }^{-1-}$ hippocampal neural cultures (DIV8) were immunostained with the indicated antibodies. Nuclei were visualized by DAPI stain. Scale bar, $100 \mu \mathrm{m}$. B, High-power images of WT and Rit ${ }^{-1-}$ neural cultures (DIV8) immunostained with the indicated antibodies. Scale bar, $50 \mu \mathrm{m}$. C, Percentage of Nestin ${ }^{+}$only (red), $\mathrm{Dcx}^{+}$only (green), Nestin ${ }^{+} / \mathrm{Dcx}{ }^{+}$(white), and Nestin ${ }^{-} / \mathrm{Dcx}{ }^{-}$(purple) cells in WT (left) and Rit ${ }^{-1-}$ (right) primary hippocampal neural culture (DIV8). The results are presented as mean \pm SEM $(n=5)$. 
positive cell. To estimate the volume of the dentate gyrus, images were collected using a Zeiss Axiovert 200M fluorescence microscope ( $10 \times$ objective). The volume of the dentate gyrus was then calculated by multiplying the area of the dentate gyrus measured using NIH ImageJ by the thickness of each section ( 40 $\mu \mathrm{m})$. Cell density was obtained by dividing total cell counts by the total volume of the dentate gyrus for the three sections that were counted. Representative images were captured using a Nikon CKX31 A1 confocal microscope (20X objective). Average granular cell layer thickness was calculated by dividing the dentate gyrus area by the length of the granular layer.

Scholl analysis. Images were acquired as a $z$-stack (1.5 $\mu \mathrm{m}$ step size) using a Nikon CKX31 A1 confocal microscope $(20 \times$ objective) from 12 -week-old WT and Rit ${ }^{-1-}$ brain sections $(40 \mu \mathrm{m})$ immunostained with Dcx. Image acquisition and quantification were performed in a blinded manner and used to create maximum intensity projections. $\mathrm{Dcx}^{+}$hippocampal DG neuron dendrites were manually traced and the total dendritic length was analyzed by NeuronJ plug-in for NIH ImageJ. To assess dendritic branching, Sholl analysis (Sholl, 1953) was performed using the Sholl analysis plug-in for NIH ImageJ. Briefly, a series of concentric circles of increasing radii (10 $\mu \mathrm{m}$ intervals) was drawn around the center of the cell body, and the number of dendrite intersections at each circle was counted. Eight to 10 neurons were analyzed for each animal, and six individual animals per genotype were examined.

Statistical analysis. All data are expressed as mean \pm SEM. The condensed nuclei counts for in vitro cell cultures, the density of $\mathrm{Dcx}^{+}$, and $\mathrm{BrdU}^{+} / \mathrm{Dcx}^{+}$neurons in dentate gyrus following CCI were analyzed using a two-way ANOVA. One-way repeated ANOVA was used to analyze dendritic branching. Newman-Keuls post hoc tests were performed when appropriate. All other studies were analyzed using Student's $t$ test. The level of statistical significance was set at $p<0.05$.

\section{Results}

Rit loss sensitizes primary hippocampal neural cultures to oxidative stress

Studies in primary mouse embryonic fibroblasts indicate that Rit signaling promotes cell survival in response to oxidative stress (Cai et al., 2011). While previous work has demonstrated Rit expression in hippocampal neurons (Wes et al., 1996; Lein et al., 2007), whether Rit-mediated prosurvival signaling is preserved in neurons is not known. To address this question, hippocampal neural cultures from newborn $\mathrm{Rit}^{-1-}$ (postnatal day 0) pups and their wild-type littermates were cultured for $8 \mathrm{DIV}$, and were left untreated or exposed to hydrogen peroxide. Neural cell death was assessed by costaining with anti-MAP2 (to identify neurons) and DAPI to monitor nuclear condensation (Fig. 1A). Despite an equivalent percentage of dead cells at baseline, Rit $^{-1-}$ hippocampal neurons displayed significantly greater dose- and time-dependent increases in neuronal cell death following hydrogen peroxide exposure (Fig. $1 B, C$ ), supporting a role for Rit in hippocampal neuron survival following oxidative damage.
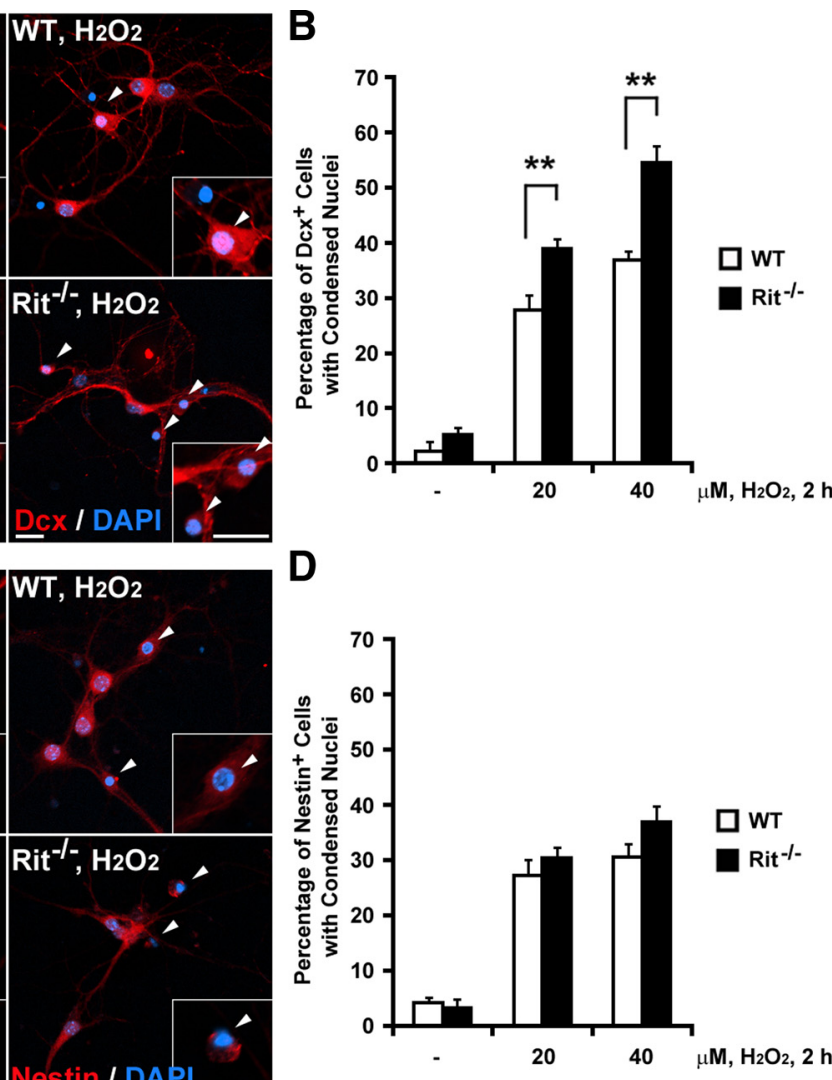

Figure 3. Rit loss sensitizes Dcx-positive neurons to oxidative stress. A, C, WT and it $^{-1-}$ hippocampal neural cultures (DIV8) insets are at higher magnification. The arrowheads indicate neurons with condensed nuclei. Scale bars, $20 \mu \mathrm{m} . \boldsymbol{B}, \boldsymbol{D}$, The percentage of $\mathrm{Dcx}^{+}(\boldsymbol{B})$ or Nestin ${ }^{+}(\boldsymbol{D})$ cells with condensed nuclei following a $2 \mathrm{~h}$ stimulation with the indicated dose of $\mathrm{H}_{2} \mathrm{O}_{2}$ are presented as mean \pm SEM (two-way ANOVA followed by Newman-Keuls post hoc test: ${ }^{* *} p<0.01, n \geq 3$ ).

\section{Rit signaling protects Dcx-positive neurons from oxidative damage}

A high level of neurogenesis is ongoing within the newborn hippocampus, which prompted us to next examine the cellular composition of our in vitro cultures. Using biomarkers specific for distinct cell types, the majority of cells at DIV8 were identified as either neural progenitor cells $\left(\mathrm{Nestin}^{+}\right)$or immature hippocampal neurons (doublecortin: $\mathrm{Dcx}^{+}$or coexpressing $\mathrm{Nestin}^{+} /$ $\mathrm{Dcx}^{+}$), with almost no cells identified as expressing the more mature neuronal marker NeuN (Fig. 2A,B). Cellular composition was not affected by Rit loss, with an equivalent number of overall (data not shown), Nestin ${ }^{+}$(WT, $20.2 \pm 3.2 \%$; Rit $^{-1-}$, $18.4 \pm 2.7 \% ; n=5 ; p=0.7), \mathrm{Dcx}^{+}\left(\mathrm{WT}, 5.5 \pm 0.6 \%\right.$; $\mathrm{Rit}^{-1-}$, $4.6 \pm 0.9 \% ; n=5 ; p=0.4)$, and Nestin $^{+} / \mathrm{Dcx}^{+}(\mathrm{WT}, 67.0 \pm$ $1.8 \%$ Rit $\left.^{-1-}, 68.1 \pm 4.2 \% ; n=5 ; p=0.8\right)$ cells observed in wild-type and Rit ${ }^{-/-}$cultures (Fig. 2C).

Since Rit loss sensitized only a fraction of cultured hippocampal neurons to hydrogen peroxide exposure, we examined whether Rit signaling selectively promoted the survival of either neural stem cells or immature neurons. To this end, wild-type and Rit $^{-1-}$ hippocampal neural cultures were left untreated or exposed to hydrogen peroxide (20 and $40 \mu \mathrm{M}$ for $2 \mathrm{~h}$ ) and were subjected to anti-Nestin or Dcx immunostaining; apoptotic cells were identified by nuclear morphology visualized using DAPI staining. As expected, hydrogen peroxide exposure resulted in a dose-dependent loss of both Nestin $^{+}$and Dcx ${ }^{+}$cells (Fig. 3). However, while Rit loss dramatically sensitized $\mathrm{Dcx}^{+}$immature 
A

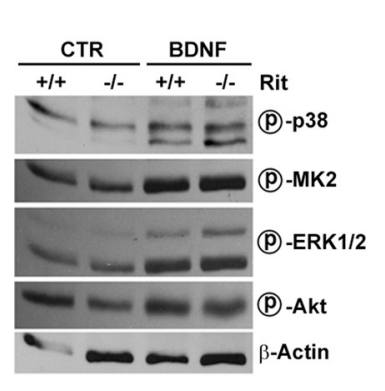

B

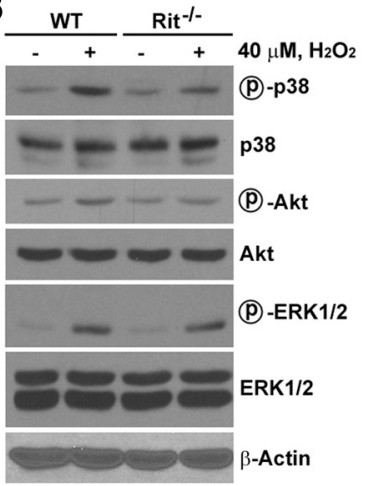

C

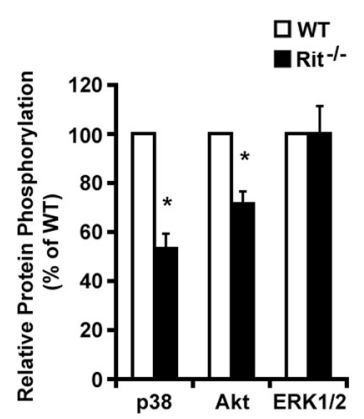

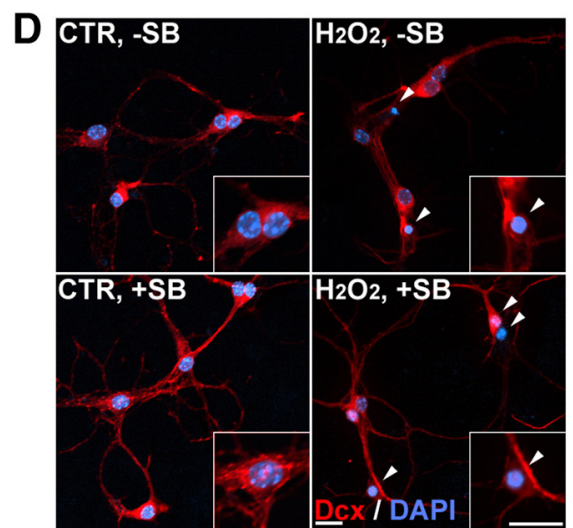

$E$

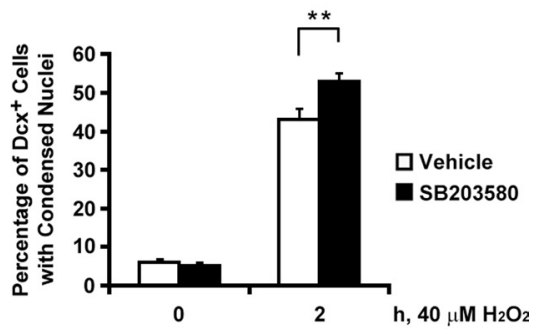

Figure 4. Rit loss disrupts ROS, but not BDNF-mediated, $\mathrm{p} 38$ and Akt activation. Lysates from WT and Rit ${ }^{-1-}$ hippocampa neurons (DIV8) were analyzed by immunoblotting with the indicated antibodies following BDNF stimulation ( $50 \mathrm{ng} / \mathrm{ml} ; 15 \mathrm{~min}$ ) (A) or $\mathrm{H}_{2} \mathrm{O}_{2}$ exposure $(40 \mu \mathrm{m} ; 15 \mathrm{~min})(\boldsymbol{B})$. C, The levels of phosphorylated p38, Akt (Ser $\left.{ }^{473}\right)$, and ERK1/2 in Rit ${ }^{-1-}$ (filled bar) relative to WT (open bar) cultures following $\mathrm{H}_{2} \mathrm{O}_{2}$ exposure are presented as mean \pm SEM (phospho-p38, $n=3$; phospho-Akt, $n=4$; phospho-ERK1/2, $n=4$; Student's $t$ test, ${ }^{*} p<0.05$ ). D, WT hippocampal neural cultures (DIV8) were left untreated (CTR) or treated with $\mathrm{H}_{2} \mathrm{O}_{2}(40 \mu \mathrm{M})$ following a preincubation with SB203580 (10 $\mu \mathrm{m} ; 30 \mathrm{~min}$ ) or vehicle (-SB) and immunostained with Dcx (red) and DAPI (blue). The insets are at higher magnification. The arrowheads indicate neurons with condensed nuclei. Scale bars, $20 \mu \mathrm{m}$. $E$, The percentage of $D c{ }^{+}$cells with condensed nucleifollowing a $2 \mathrm{~h}$ stimulation with $\mathrm{H}_{2} \mathrm{O}_{2}(40 \mu \mathrm{m})$ following either SB203580 or vehicle preincubation are presented as mean \pm SEM (two-way ANOVA followed by Newman-Keuls post hoc test: $\left.{ }^{* *} p<0.01, n \geq 7\right)$.

neurons to oxidative stress $\left(40 \mu \mathrm{M} \mathrm{H}_{2} \mathrm{O}_{2}\right.$; WT, $36.8 \pm 3.4 \%$; Rit $^{-1-}, 54.6 \pm 6.6 \% ; n=5 ; p<0.01$ ) (Fig. $3 A, B$ ), the survival of Nestin ${ }^{+}$neural stem cells was not affected $\left(40 \mu \mathrm{M} \mathrm{H}_{2} \mathrm{O}_{2}\right.$; WT, $30.6 \pm 5.3 \%$; Rit $\left.^{-1-}, 36.9 \pm 6.4 \% ; n=4 ; p=0.45\right)($ Fig. $3 C, D)$.

\section{Rit is not required for hippocampal BDNF signaling}

In addition to its established role in the control of neuronal development and synaptic plasticity, BDNF-TrkB signaling recently has been found to play a critical role in adult hippocampal neurogenesis, in part by regulating neural progenitor cell proliferation within the dentate gyrus (Bergami et al., 2008; Li et al., 2008). Since previous studies have identified Rit in the coupling of neurotrophin signaling to MAP kinase activation (Spencer et al., 2002b; Shi and Andres, 2005; Rudolph et al., 2007; Cai et al., 2011; Shi et al., 2011), and BDNF stimulation is known to promote robust neural MAPK cascade activation (Reichardt, 2006), we assessed the contribution of Rit to hippocampal BDNF-mediated signaling. BDNF exposure led to robust ERK, p38, MK2, and Akt activation in wild-type hippocampal neural cultures, as monitored by anti-phosphospecific immunoblotting. However, BDNF-mediated kinase signaling was not significantly altered in Rit-null cells (Fig. 4A).

Rit loss impairs ROS-mediated p38 MAPK and Akt signaling

Recent studies have identified Ritmediated activation of the p38-HSP27Akt cascade as playing an important role in oxidative stress survival (Cai et al., 2011; Shi et al., 2011). To determine whether a similar molecular mechanism may support neural survival, wild-type and $\mathrm{Rit}^{-1-}$ hippocampal cultures were exposed to hydrogen peroxide ( $40 \mu \mathrm{M}$ for $15 \mathrm{~min}$ ). Consistent with a role for Rit in the regulation of this cascade, antiphosphospecific p38 MAP kinase [53.3 \pm $6.2 \%$ of WT $(n=3 ; p<0.05)]$ and Akt [71.6 $\pm 5.1 \%$ of WT $(n=4 ; p<0.05)]$ immunoblotting demonstrated that ROSdependent activation of both kinases was decreased in Rit-null hippocampal cultures when compared with similarly treated wild-type cells (Fig. 4B,C). Importantly, Rit does not participate in all hydrogen peroxide-mediated MAPK signaling as ERK activation was not altered by Rit loss [99.9 $\pm 11.7 \%$ of WT ( $n=4$; $p=0.99)]($ Fig. $4 B, C)$.

We have recently demonstrated that Rit loss selectively alters the coupling of oxidative stress to intracellular prosurvival signaling pathways, particularly p 38 dependent Akt activation (Cai et al., 2011; Shi et al., 2011). To determine whether p38 signaling also contributes importantly to oxidative stress protection in neurons, hippocampal neurons (DIV8) from wild-type mice were pretreated with the p38 inhibitor SB203580 (10 $\mu \mathrm{M})$ before hydrogen peroxide exposure. Figure $4 D$ shows representative images of vehicle (control)- or SB203580-treated hippocampal neurons following $\mathrm{H}_{2} \mathrm{O}_{2}$ exposure. While SB203580 treatment had no effect on cell viability in the absence of stress, p38 inhibition significantly increased the incidence of nuclear condensation following hydrogen peroxide exposure $(40 \mu \mathrm{M}, 2 \mathrm{~h}$ : WT, $43.1 \pm 2.7 \%$; $\mathrm{Rit}^{-1-}, 52.9 \pm 2.3 \% ; n \geq 7 ; p<0.01$ ) (Fig. $4 E)$. These results support a critical role for $\mathrm{p} 38$ signaling in the survival of hippocampal neurons responding to oxidative stress.

\section{Rit loss alters dendritic growth in the developing hippocampus}

Newborn neurons are continuously born within the subgranular zone (SGZ) of the adult hippocampus, but the majority of newborn neurons undergo apoptosis, with only the fraction that functionally integrate surviving (Zhao et al., 2008; Ming and Song, 2011). Since Rit loss attenuates the in vitro survival of cultured newborn hippocampal neurons, we examined the effect of Rit loss on neuronal development within the dentate gyrus granular layer. Rit ${ }^{-1-}$ mice did not display any gross morphological changes to the hippocampus (Fig. 5), consistent with the lack of obvious developmental defects in other tissues (Cai et al., 2011). The cellular density of $\mathrm{Dcx}^{+}$immature neurons and the average thickness of the granular layer of the dentate gyrus was un- 
changed between $\mathrm{Rit}^{-1-}$ and wild-type littermates at two different ages (12 and 20 weeks) (Fig. 5B-D).

While the cellular density of $\mathrm{Dcx}^{+}$neurons was not altered in $\mathrm{Rit}^{-1-}$ mice, we noted that the processes of these neurons appeared to differ from those in wild-type controls (Fig. 5B). Since we previously demonstrated a role for Rit in controlling neuronal morphogenesis, contributing to the regulation of axonal versus dendritic growth modes in cultured hippocampal neurons (Lein et al., 2007), we examined the effect of Rit loss on the dendritic morphology of $\mathrm{Dcx}^{+}$neurons. Representative camera drawings of the dendritic arbor of anti-Dcx immunostained hippocampal neurons (Fig. 6A,B) demonstrate that Rit loss significantly reduced total dendritic length (WT, $368 \pm 11 \mu \mathrm{M}$; Rit ${ }^{-/-}, 296 \pm 10$ $\mu \mathrm{M} ; n=6 ; p<0.01$ ) (Fig. $6 C$ ) and dendritic complexity (Fig. $6 D$ ), as assessed by Sholl analysis [20-25\% decrease at peak (distance of $90-110 \mu \mathrm{m})$ relative to WT; $n=6 ; p<0.05]$.

\section{Increased loss of hippocampal neurons in Rit-null mice following CCI}

TBI causes delayed neuronal dysfunction and death through a variety of secondary processes, with oxidative stress being a major contributor to neurodegeneration (Lewén et al., 2000; Bains and Hall, 2012). To examine the in vivo effect of Rit deficiency following TBI, we performed FJC staining following CCI, an experimental model of contusion TBI. The volume of neocortical tissue damage was equivalent for wild-type $(14.3 \pm 2.8 \% ; n=4)$ and Rit-null (14.2 $\pm 4.9 \% ; n=8)$ animals at $24 \mathrm{~h}$ after injury (Fig. $7 A$ ). Consistent with previous reports (Rola et al., 2006; Gao et al., 2008), CCI resulted in hippocampal neuronal degeneration concentrated in the dentate gyrus, as reflected by an increased number of FJC-positive neurons (Fig. 7 B,D). Quantification of FJC staining in subregions of the hippocampus revealed that the majority of degenerating neurons in wild-type mice $(\sim 80 \%)$ were located within the inner granular layer (including the SGZ and inner one-third of the granular layer) of the dentate gyrus, where immature neurons and neural stem cells reside. Many fewer FJC-positive neurons were observed in the outer granular layer or hilus, and almost no degenerating neurons were seen in the CA3 or CA1 regions (Fig. $7 B, C)$. Importantly, $\mathrm{Rit}^{-1-}$ mice displayed almost twice the number of FJCpositive cells (WT, $n=9: 391 \pm 30$; Rit $\left.^{-I-}, n=7: 620 \pm 62 ; p<0.01\right)$, with the majority located within the inner granular layer (WT, $n=9: 315 \pm 23$; $\left.\mathrm{Rit}^{-1-}, n=7: 498 \pm 53 ; p<0.05\right)$. DAPI staining identified a concentration of cells with condensed nuclei within this same region (Fig. 7D).

\section{Rit regulates newborn immature} neuron survival following CCI

There are a variety of cell types within the dentate gyrus, each with distinct neural functions, morphology, and electrophysiological properties (Ming and Song, 2011). BrdU labeling detected equal numbers of dividing cells in naive wild-type and $\mathrm{Rit}^{-1-}$ mice $48 \mathrm{~h}$ after the last of seven daily BrdU injections, indicating that basal subgranular progenitor cell prolifer-
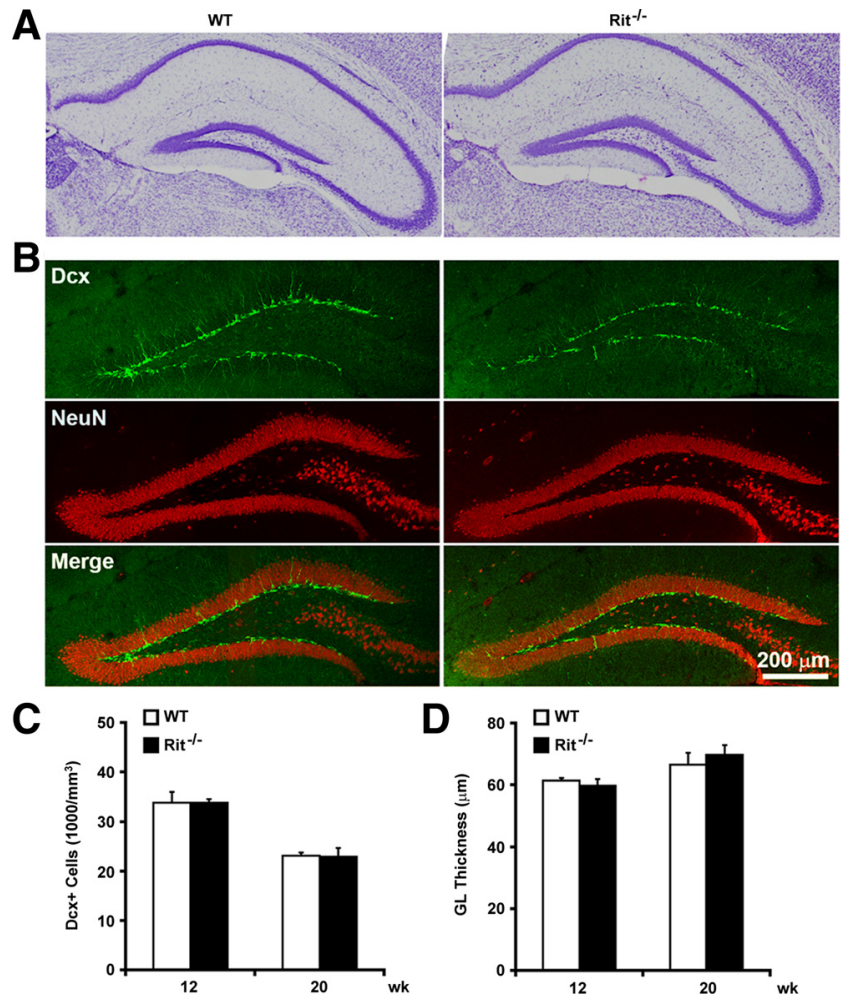

Figure 5. Rit loss does not disrupt brain development or adult neurogenesis. $\boldsymbol{A}$, Representative images of Nissl-stained sections from 12 -week-old WT and Rit ${ }^{-1-}$ mice. $\boldsymbol{B}$, Representative confocal images of the dentate gyrus of 12 -week-old WTand Rit ${ }^{-1-}$ mice immunostained for Dcx (green) and NeuN (red). C, Dcx ${ }^{+}$immature neuron density is not significantly different in $\mathrm{Rit}^{-/-}$mice compared with WT mice at 12 or 20 weeks of age. Results are presented as mean \pm SEM (Student's $t$ test, 12 weeks, $p=0.98, n=4 ; 20$ weeks, $p=0.92, n=4)$. $\boldsymbol{D}$, Average thickness of the dentate gyrus granular layer is unchanged in Rit ${ }^{-1-}$ mice. Results are presented as mean \pm SEM (Student's $t$ test, 12 weeks, $p=0.5, n=4 ; 20$ weeks, $p=0.54, n=4$ ).

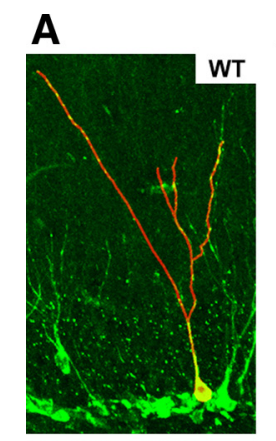

B
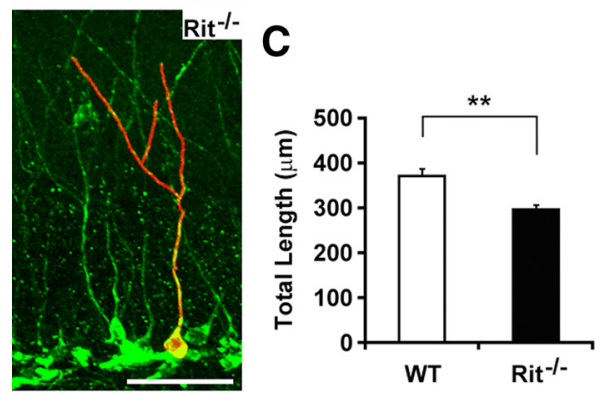
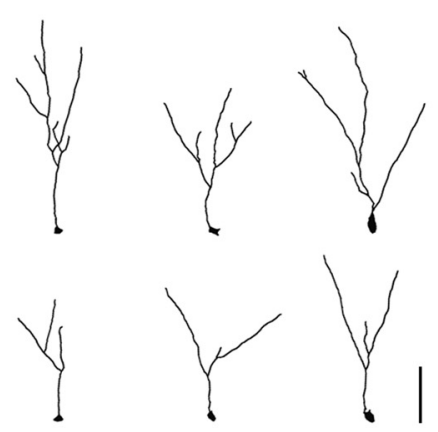

D

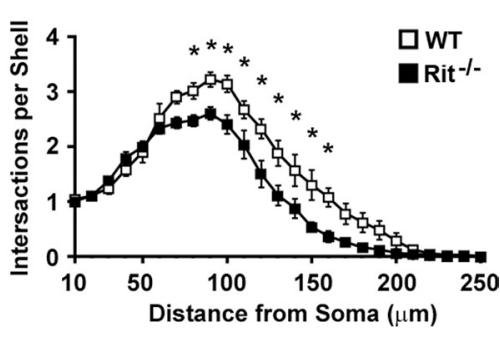

Figure 6. Rit loss impairs in vivo dendritic growth of $D c x^{+}$hippocampal neurons. $\boldsymbol{A}, \boldsymbol{B}$, Representative confocal images $(\boldsymbol{A})$ and dendrite tracing images $(\boldsymbol{B})$ of Dcx ${ }^{+}$immature neurons from WT and Rit $^{-/-}$animals (green: Dcx immunostaining; red: computer neurite tracing). Scale bar, $50 \mu \mathrm{m}$. C, Total dendritic length of WT and Rit ${ }^{-1-} \mathrm{Dcx}{ }^{+}$immature hippocampal neurons (Student's $t$ test, ${ }^{* *} p<0.01 ; n=6$ ). $D$, Sholl analysis of WT and Rit ${ }^{-1-} \mathrm{Dcx}{ }^{+}$immature hippocampal neurons (one-way repeated ANOVA followed by Newman-Keuls post hoc test, ${ }^{*} p<0.05 ; n=6$ ). 
A
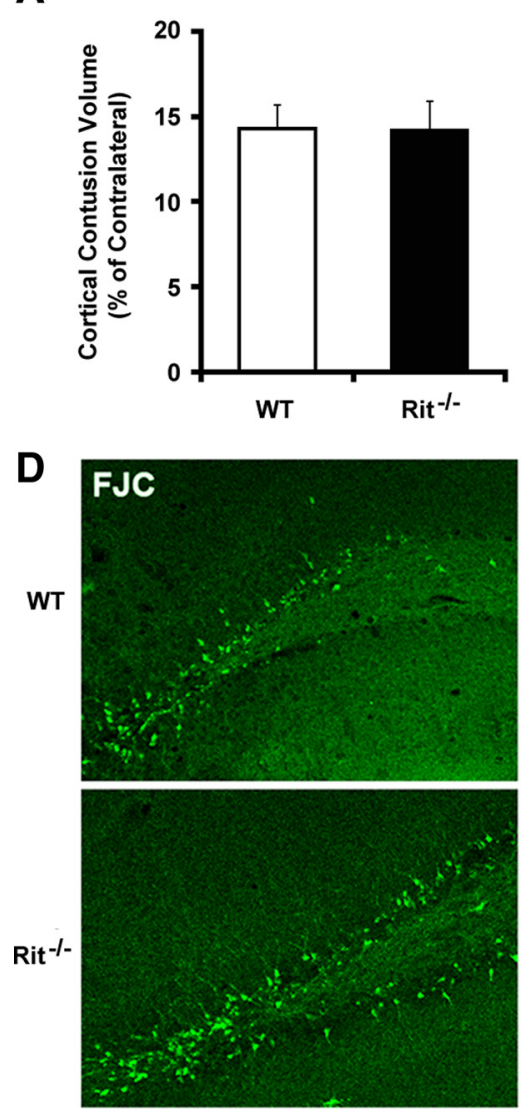

B

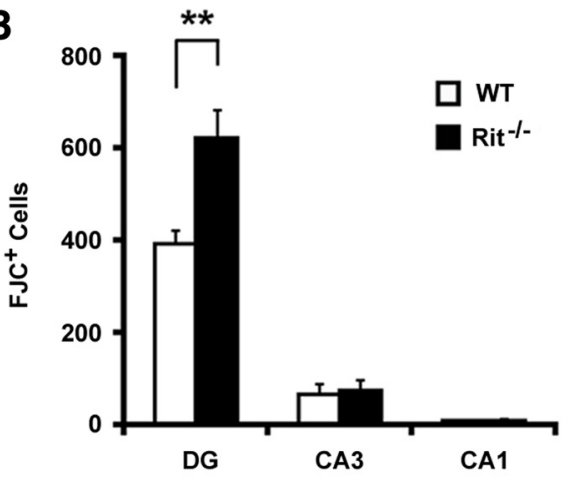

C

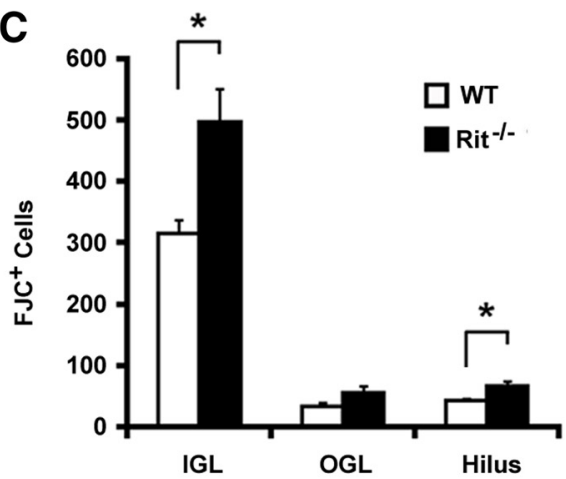

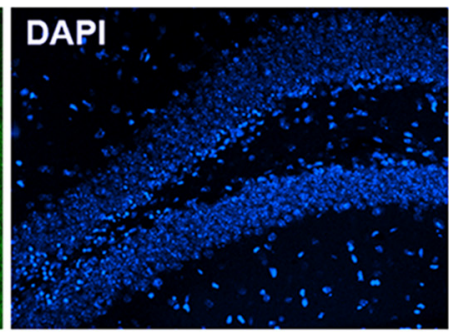
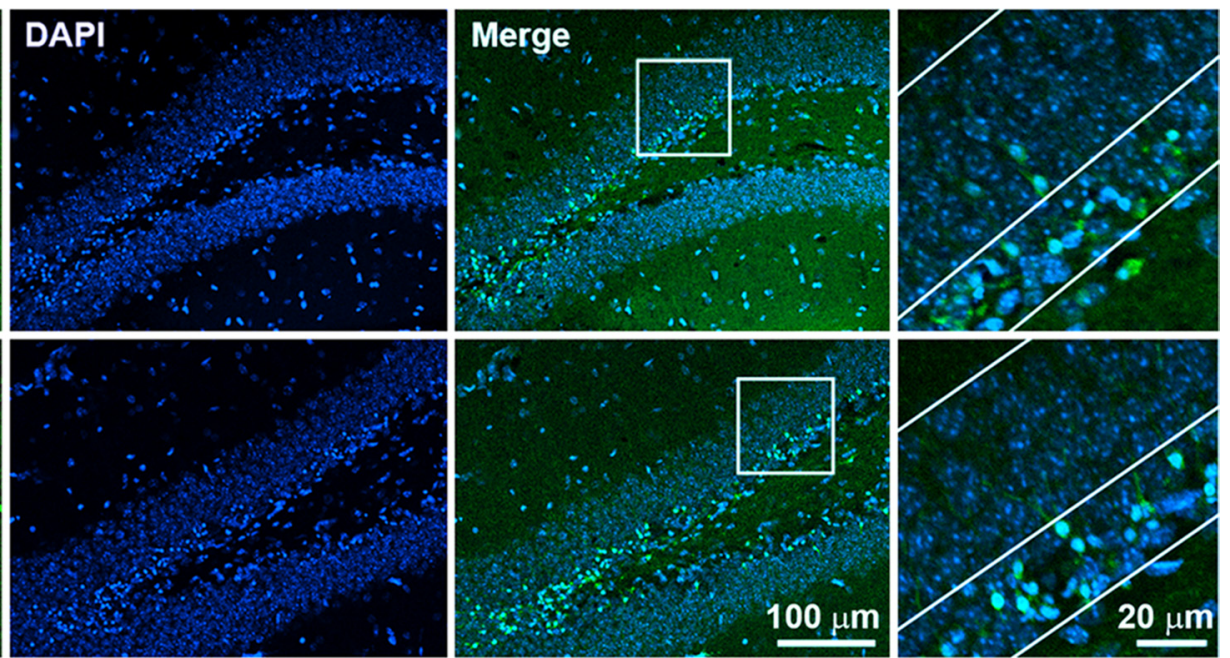

Figure 7. Rit contributes to neuronal survival within the dentate gyrus following CCI. $A_{1}$ Cortical contusion volume in the ipsilateral hemisphere relative to the contralateral hemisphere in WT and Rit $^{-1-}$ littermates was similar $24 \mathrm{~h}$ after injury. Data are presented as mean $\pm \mathrm{SEM}\left(\mathrm{WT}, n=4 ;\right.$ Rit $^{-1-}, n=8 ; t$ test, $\left.p=0.97\right)$. B, Regional distribution of FJC-positive cells in the hippocampus. The results are presented as mean \pm SEM (WT, $n=9$; Rit ${ }^{-1-}, n=7$; Student's $t$ test, $\left.{ }^{* *} p<0.01\right)$. C, Subregional distribution of FJC-positive cells in the dentate gyrus (DG). The results are presented as mean \pm SEM for the inner granular layer (IGL), outer granular layer (OGL), and hilus (WT, $n=9$; Rit ${ }^{-1-}, n=7$; Student's $t$ test, ${ }^{*} p<0.05$ ). $\boldsymbol{D}$, Representative confocal images of the ipsilateral dentate gyrus costained with FJC (green) and DAPI (blue) from WT and Rit ${ }^{-1-}$ littermates at $24 \mathrm{~h}$ following $\mathrm{CCl}$. The insets are at higher magnification; the lines identify the inner granular layer.

ation was not affected by Rit loss (Fig. $8 A, B$ ). Costaining with BrdU and Dcx was used to evaluate the degree of adult neurogenesis, with uninjured (sham) wild-type and $\mathrm{Rit}^{-/-}$mice displaying equal numbers of $\mathrm{BrdU}^{+} / \mathrm{Dcx}^{+}$newborn immature neurons within the dentate gyrus (Fig. $8 E, F$ ).

Concussive injury results in a marked loss of $\mathrm{Dcx}^{+}$neurons in the dentate gyrus of the ipsilateral hemisphere $(23 \pm 9 \%$ loss relative to shams at $24 \mathrm{~h}$ and $29 \pm 8 \%$ at $48 \mathrm{~h}$ ) in wild-type mice, with only a small decrease within the contralateral dentate gyrus (Fig. $8 C, D$ ). The reduction in $\mathrm{Dcx}^{+}$cells was significantly more severe in $\mathrm{Rit}^{-1-}$ mice $(p<0.05$, effect of genotype; $p<0.05$, interaction of genotype with injury condition), resulting in the loss of $40 \pm 8 \%$ of $\mathrm{Dcx}^{+}$cells at $24 \mathrm{~h}$, and $44 \pm 11 \%$ of immature neurons $48 \mathrm{~h}$ after injury $\left(24 \mathrm{~h}, \mathrm{WT}, n=9: 24 \pm 1 \times 10^{3} / \mathrm{mm}^{3}\right.$; $\mathrm{Rit}^{-1-}, n=7: 20 \pm 1 \times 10^{3} / \mathrm{mm}^{3}, p<0.05 ; 48 \mathrm{~h}$, WT, $n=10$ : $\left.22 \pm 1 \times 10^{3} / \mathrm{mm}^{3} ; \mathrm{Rit}^{-\prime-}, n=9: 19 \pm 1 \times 10^{3} / \mathrm{mm}^{3}, p=0.07\right)$ (Fig. $8 A, C$ ). Importantly, while the number of $\mathrm{BrdU}^{+} / \mathrm{Dcx}^{+}$cells within the dentate gyrus decreased in wild-type mice at $48 \mathrm{~h}$ after CCI injury ( $35 \pm 14 \%$ ) relative to sham controls, the loss of $\mathrm{BrdU}^{+} /$ $\mathrm{Dcx}^{+}$neurons in $\mathrm{Rit}^{-1-}$ mice was significantly greater with a loss of $59 \pm 18 \%$ of newborn neurons within the inner granular layer of the dentate gyrus ( $48 \mathrm{~h}, \mathrm{WT}, n=10: 5.0 \pm 0.3 \times 10^{3} / \mathrm{mm}^{3}$; $\mathrm{Rit}^{-/-}, n=$ 9: $3 \pm 0.5 \times 10^{3} / \mathrm{mm}^{3} ; p<0.05$ ) (Fig. $8 E$ ).

Early posttraumatic loss of immature hippocampal neurons is followed by the activation of neural stem/progenitor cells, leading to increased neurogenesis and a return of $\mathrm{Dcx}{ }^{+}$ cell numbers to preinjury levels by $14 \mathrm{~d}$ after TBI (Rola et al., 2006). To examine the in vivo effect of Rit deficiency on postTBI recovery, brains collected from mice $14 \mathrm{~d}$ following either sham or CCI injury were immunostained for Dcx (Fig. 9A). In wild-type mice, TBI resulted in a marked increase in numbers of $\mathrm{Dcx}^{+}$immature neurons in the dentate gyrus of the ipsilateral hemisphere (WT, sham, $n=5,30.2 \pm 1.4 \times 10^{3} / \mathrm{mm}^{3}$; CCI, $n=8,37.7 \pm 3.3 \times 10^{3} / \mathrm{mm}^{3} ; p<0.05$ ) (Fig. $9 B$ ), with only a modest increase within the contralateral dentate gyrus (Fig. 9C). In stark contrast, numbers of $\mathrm{Dcx}^{+}$cells within the ipsilateral hemisphere of brain-injured $\mathrm{Rit}^{-1-}$ mice remained at or below sham controls ( $\mathrm{Rit}^{-/-}$, sham, $n=5,29.0 \pm 1.5 \times$ $10^{3} / \mathrm{mm}^{3}$; CCI, $n=9,26.5 \pm 1.2 \times 10^{3} / \mathrm{mm}^{3}$ ) (Fig. 9B), and were significantly lower than in brain-injured wild-type mice $(p<0.01)$. The differential between $\mathrm{Dcx}^{+}$cell numbers in $\mathrm{Rit}^{-1-}$ and wild-type mice is even greater at $14 \mathrm{~d}$ (WT, $14 \mathrm{~d}$, $n=8,123.3 \pm 6.0 \%$ Rit $\left.^{-\prime-}, 14 \mathrm{~d}, n=9,89.1 \pm 6.6 \%\right)$ than at $48 \mathrm{~h}$ (WT, 48 h, $n=10,80.7 \pm 3.1 \%$; Rit ${ }^{-1-}, 48$ h, $n=9$, $64.9 \pm 3.4 \%$ ) following concussive injury (Fig. 9D), suggesting that Rit loss not only enhances immature neuron death but also impedes CCI-mediated recovery, blunting the repopulation of adult born neurons within the dentate gyrus relative to wild-type controls. 


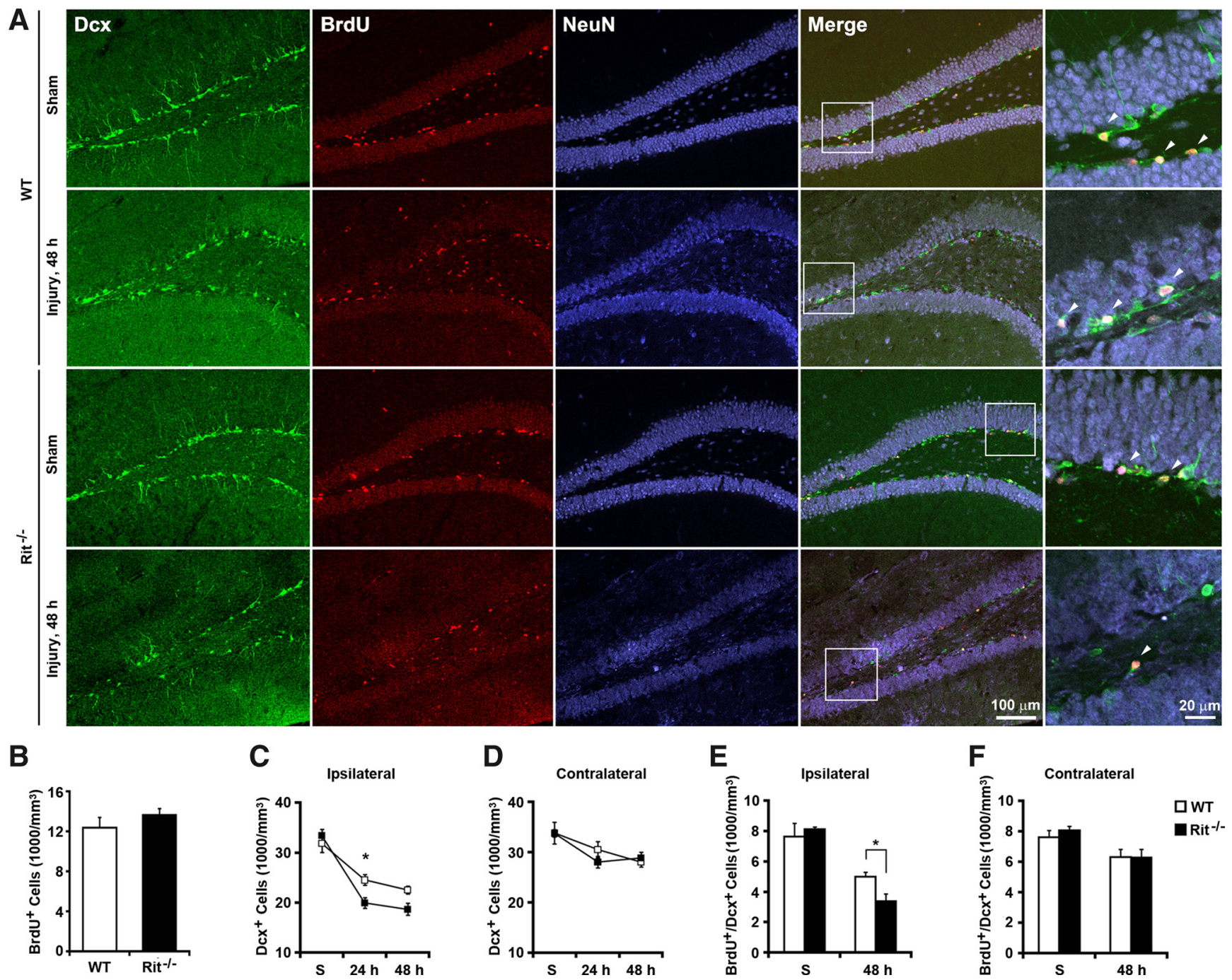

Figure 8. Rit loss selectively impairs newborn neuron survival following $\mathrm{CCl}$. A, WT and Rit ${ }^{-1-}$ mice were injected daily with BrdU ( $\left.50 \mathrm{mg} / \mathrm{kg}\right)$ for 1 week before either sham or $\mathrm{CCl}$ injury. Representative coronal hippocampal sections coimmunostained for $D c x$ (green), BrdU (red), and NeuN (blue). The insets are at higher magnification; the arrowheads indicate BrdU/Dcx-double positive cells. B, Quantification of total BrdU ${ }^{+}$cells within the dentate gyrus. The results are presented as mean \pm SEM (Student's t test, $p=0.3 ; n=6$ per genotype). Quantification of Dcx ${ }^{+}$cells within the ipsilateral $(\boldsymbol{C})$ and contralateral ( $\boldsymbol{D})$ dentate gyrus of WT (open) and Rit ${ }^{-1-}$ (filled) mice after sham (S) or CCl (24 and 48 h) injury. Loss of Dcx ${ }^{+}$cells after brain injury $(p<0.0001$, injury effect) was significantly exacerbated by Rit deficiency ( $p<0.05$, injury by genotype interaction). Results are presented as mean \pm SEM ( ${ }^{*} p<0.05 ;$ Sham, $n=6-7 ; 24 \mathrm{~h}, n=7-9 ; 48 \mathrm{~h}, n=$ 9-10). Quantification of BrdU ${ }^{+} / \mathrm{Dcx}^{+}$cells within the ipsilateral $(\boldsymbol{E})$ and contralateral $(\boldsymbol{F})$ dentate gyrus of WT (open bar) and Rit $^{-1-}$ (filled bar) mice after sham $(S)$ or $C(\mathrm{Cl}(48 \mathrm{~h})$ injury. Results are presented as mean \pm SEM (WT, sham, $n=7 ; 48 \mathrm{~h}, n=10 ;$ Rit $^{-\prime-}$, sham, $n=6 ; 48 \mathrm{~h}, n=9$; two-way ANOVA followed by Newman-Keuls post hoc test, ${ }^{*} p<0.05$ ).

\section{Discussion}

The discovery of neural stem cells in the adult mammalian brain has motivated studies to understand both the regulation and potential therapeutic enhancement of neurogenesis for the treatment of various neuropathologies, including TBI (Zhao et al., 2008; Ming and Song, 2011). The initial excitement over the potential for self-repair has been tempered by the demonstration that contusive TBI results in the selective death of immature neurons (Gao et al., 2008), compromising the very cell population poised to compensate for trauma-induced neuronal loss within the dentate gyrus. Experimental blockade of the hippocampal neurogenic response exacerbates cognitive dysfunction following TBI (Blaiss et al., 2011), emphasizing the need to better understand the response of progenitors and newborn neurons to trauma. Here, we find that deficiency of the Rit GTPase markedly enhances the vulnerability of adult-born immature hippocampal neurons in response to CCI brain injury. These data suggest that
Rit plays a critical role in the survival of newborn hippocampal neurons following brain injury.

A critical determinant of neuronal connectivity is apoptosis, which is essential to normal brain development, occurring in both the fetal and postnatal brain (Buss et al., 2006). Apoptotic signaling pathways are triggered by various molecular cues, one of the most common being ROS (Lin and Beal, 2006). TBIinduced ROS has been linked to increased neuronal apoptosis, an effect blocked by agents that decrease intracellular ROS levels (Lewén et al., 2000). Our findings indicate that Rit-dependent signaling is a key mediator of the cellular response of immature hippocampal neurons to oxidative stress. Importantly, TBI dramatically increases immature neuron loss in the dentate gyrus of $\mathrm{Rit}^{-1-}$ mice, establishing Rit as an important neuronal survival mechanism. These studies extend our understanding of Ritmediated protection to neurons, and suggest a critical role for Rit in injury-induced neurogenesis, particularly the control of cellu- 
A

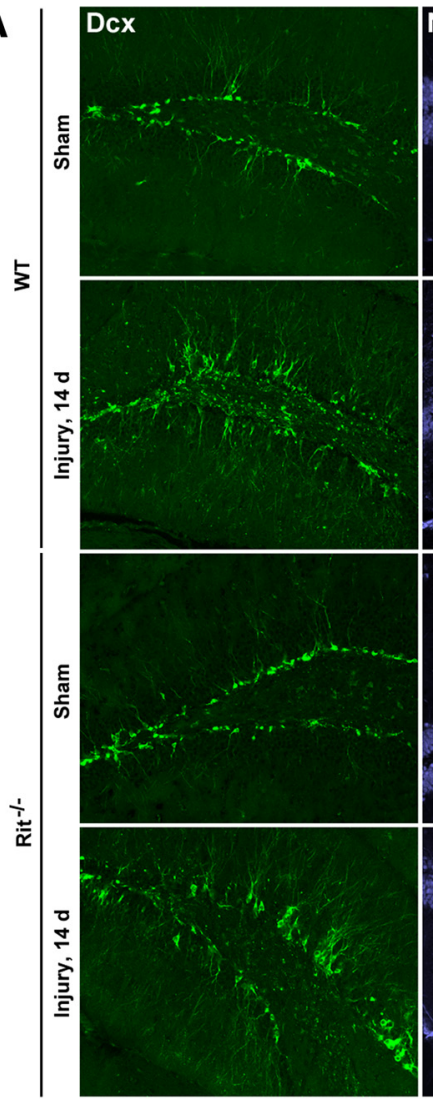

B

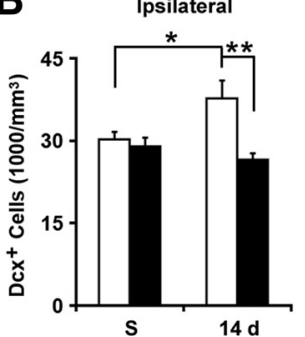

C

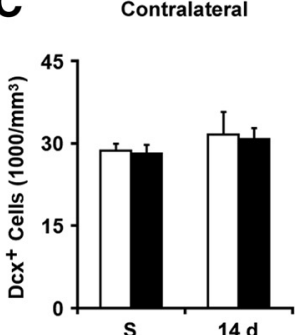

D
Merge

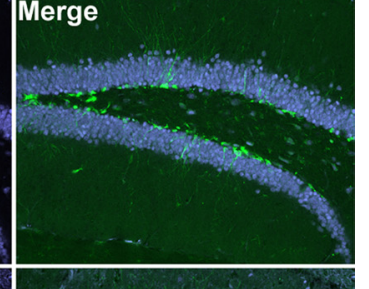

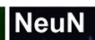
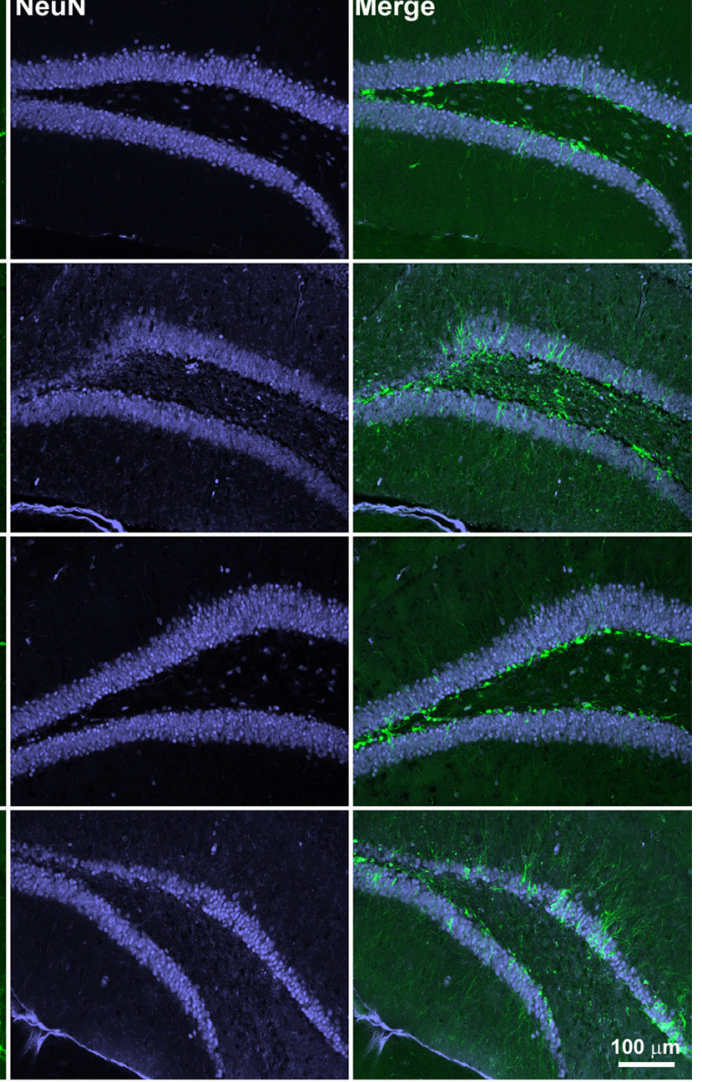

100

口WT

Figure 9. Rit loss significantly impairs the recovery of newborn immature neuron population following CCl. $\boldsymbol{A}$, WT and Rit ${ }^{-1-}$ mice were subjected to sham or CCl injury and allowed $14 \mathrm{~d}$ of recovery. Representative coronal hippocampal sections coimmunostained for Dcx (green) and NeuN (blue) are shown. Quantification of Dcx ${ }^{+}$cells within the ipsilateral (B) and contralateral ( $(\boldsymbol{C})$ dentate gyrus of WT (open bar) and Rit ${ }^{-1-}$ (filled bar) mice $14 \mathrm{dfollowing} \mathrm{sham}(\mathrm{S})$ or CCl injury. Results are presented as mean \pm SEM (WT, sham, $n=5 ; 14 \mathrm{~d}, n=8$; Rit ${ }^{-1-}$, sham, $n=5 ; 14 \mathrm{~d}, n=9$; two-way ANOVA followed by Newman-Keuls post hoc test: $\left.{ }^{*} p<0.05,{ }^{* *} p<0.01\right)$. D, Percentage of $\mathrm{Dcx}{ }^{+}$cell recovery in the ipsilateral hemisphere relative to that in the contralateral hemisphere in sham, and at $24 \mathrm{~h}, 48 \mathrm{~h}$, and $14 \mathrm{~d}$ following $\mathrm{CCl}$. Note the deficit in Rit ${ }^{-1-}$ neuronal recovery following $\mathrm{CCl}_{\text {. }}$

lar repair and regenerative mechanisms implicated in the network remodeling that occurs following brain injury. These data are, to our knowledge, the first to identify a role for a Ras family GTPase in a select subpopulation of developing neurons, playing a critical role in the survival of immature hippocampal neurons in response to injury, without apparent impact on basal hippocampal neurogenesis. However, hippocampal $\mathrm{Dcx}^{+}$neurons from Rit $^{-1-}$ mice displayed shortened dendrites and decreased arborization (Fig. 6). Studies are underway to determine whether Rit contributes to the maturation and/or functional integration of these neurons.

While a detailed molecular mechanism for Rit-mediated neural survival requires further investigation, the reduction in p38 and Akt activity observed in $\mathrm{Rit}^{-1-}$ neural cultures in response to oxidative stress (Fig. $4 B, C$ ) suggests that the recently characterized Rit-p38-Akt signaling axis is involved in directing neuronal sur- vival (Cai et al., 2011; Shi et al., 2011). Indeed, Akt is activated following TBI (Zhang et al., 2006; Madathil et al., 2010) and plays a central role downstream of neurotrophic and growth factor receptors to promote neural survival (Reichardt, 2006). The PI3K/AKT/mTOR/GSK3 $\beta$ pathway has been suggested to be critical to controlling neuronal growth and polarity (Backman et al., 2001; Kwon et al., 2006). Indeed, recent studies have shown that deletion of Pten in adult neural stem cells results in pronounced Akt activation, and the generation of mature granule neurons with elongated dendrites and increased arborization (Amiri et al., 2012). Whether Rit contributes to Akt/ mTOR/GSK $3 \beta$-dependent regulation of axonal and dendritic growth in granule neurons awaits further characterization. Numerous studies have found that stressmediated p38 activation can lead to either cell death or recovery, depending on both the severity of the stimulus and the nature of the cell (Wagner and Nebreda, 2009). These studies have implicated p38 in the regulation of additional prosurvival pathways, including the activation of MEF2 (Mao et al., 1999), $\beta$-catenin (Thornton et al., 2008), and CREB (Arthur et al., 2004), expanding the potential role for Rit in influencing neuronal recovery.

Brain injury comprises a complex set of stimuli that have often conflicting roles in the regulation of neurogenesis. For example, glutamate has been implicated in the enhancement of neurogenesis, but also excitotoxicity (Mattson, 2008). Because Rit is activated by a variety of cellular stimuli, including a range of extracellular ligands, inflammatory cytokines, and cellular stresses (Shi et al., 2011), additional studies are needed to determine whether in vivo stimuli beyond ROS are involved in Rit activation following brain injury. It also remains to be determined whether Rit plays a similar role in the control of neurogenesis in response to environmental influences. For example, environmental stress has been reported to enhance programmed cell death (Gould et al., 1997), whereas exposure to an enriched environment, learning, and synaptic activity can result in increased survival of adultborn neurons (Kempermann et al., 1997; Young et al., 1999; Petreanu and Alvarez-Buylla, 2002). Finally, Rit is expressed in glia cells, and it will be important to determine whether glia-derived Rit contributes to the neurotrophic actions of non-neuronal cells following injury. Studies are underway to determine whether Rit signaling participates in these control mechanisms.

Precise control of the generation and elimination of adultborn neurons is critical to the maintenance of the adult nervous system (Zhao et al., 2008; Ming and Song, 2011). Similar to embryonic brain development, overproduction of progenitor cells and immature neurons in the adult brain results in the apoptosis of $60-80 \%$ of all adult-born neurons during maturation (Sun et 
al., 2004; Kuhn et al., 2005). Analysis of Bax knock-out mice indicates that programmed cell death is the default pathway for adult-born neurons (Sun et al., 2004), counteracted by signaling cascades promoting survival. Rescue mechanisms involving the actions of neurotransmitters, neuropeptides, and growth factors have been proposed to regulate hippocampal neurogenesis $(\mathrm{Mu}$ et al., 2010) and Ras family GTPases have established roles in coupling these ligands to the activation of cell survival pathways (Colicelli, 2004; Reichardt, 2006). Among these agents, BDNF has been shown to play a role in regulating hippocampal neurogenesis, promoting the survival of adult-born neurons (Bergami et al., 2008; Li et al., 2008). Despite previous studies identifying a role for Rit in coupling neurotrophin signaling to MAPK cascade activation (Spencer et al., 2002a; Lein et al., 2007; Rudolph et al., 2007), BDNF signaling was not altered in Rit-null hippocampal cultures (Fig. $4 A$ ), indicating that Rit does not play a critical role downstream of BDNF-TrkB in the hippocampus. Indeed, the absence of any gross morphological changes to the hippocampus (Fig. 5) and lack of broader developmental defects in the CNS (Cai et al., 2011) suggest that Rit signaling is not essential for neurotrophin signaling during either embryonic development or normal adult neurogenesis.

A surprising finding of the current study is that, while Rit plays a central role in promoting immature $\mathrm{Dcx}^{+}$neuronal survival following TBI, it was not required for the maintenance of basal immature adult-born neurons or normal hippocampal development (Fig. 7). Neither cortical contusion volume nor the number of degenerating hippocampal pyramidal neurons were significantly elevated in Rit-null animals following CCI injury (Fig. 6), emphasizing the selective role played by Rit signaling in adultborn immature granule neuron survival in the dentate gyrus. What may underlie this signaling specificity? There appear to be two critical survival periods during adult neurogenesis (Ming and Song, 2011), one at the intermediate progenitor stage (Sierra et al., 2010) and a second at the immature neuron integration stage (Tashiro et al., 2006). In vitro analysis suggests that the hippocampal neurogenic niche provides a microenvironment and growth factors needed to maintain stem cell self-renewal and homeostasis (Zhao et al., 2008; Ming and Song, 2011), while integration into the hippocampal circuitry provides neurotrophic support for mature granular neurons (Minichiello and Klein, 1996; Reichardt, 2006). As discussed above, Rit loss does not significantly impact BDNF-dependent neuronal signaling, which is reminiscent of a recent study demonstrating that EGF signaling is unaffected in $\mathrm{Rit}^{-1-}$ embryonic fibroblasts (Cai et al., 2011). Thus, both neural stem cell and mature granular neuron survival appears to be dependent upon growth factor signaling pathways that do not rely on Rit function. A similar reliance on trophic/growth factor support has not been described for the survival of immature neurons, perhaps making this cell population uniquely susceptible to stress-mediated apoptosis, and therefore particularly dependent upon Rit activity. Rit deficiency also negatively impacted recovery following brain injury, compromising the full recovery of $\mathrm{Dcx}^{+}$neurons seen in wild-type mice (Fig. 9). Studies are underway to examine whether this delay results from the need to rebuild cell populations from a greater initial deficit, or whether Rit also contributes to the survival or the dynamics of neural progenitor activation in the traumatically injured brain.

In summary, our data identify Rit as playing a key role in the regulation of adult hippocampal neurogenesis in response to injury, by controlling adult-born immature neuron survival. Modulating the activation status of Rit may function to regulate neurogenesis in response to a range of environmental cues. If so, therapeutic strategies targeting Rit activation may prove particularly effective in promoting endogenous recovery/repair following traumatic injury.

\section{References}

Amiri A, Cho W, Zhou J, Birnbaum SG, Sinton CM, McKay RM, Parada LF (2012) Pten deletion in adult hippocampal neural stem/progenitor cells causes cellular abnormalities and alters neurogenesis. J Neurosci 32:5880-5890.

Arthur JS, Fong AL, Dwyer JM, Davare M, Reese E, Obrietan K, Impey S (2004) Mitogen- and stress-activated protein kinase 1 mediates cAMP response element-binding protein phosphorylation and activation by neurotrophins. J Neurosci 24:4324-4332.

Backman SA, Stambolic V, Suzuki A, Haight J, Elia A, Pretorius J, Tsao MS, Shannon P, Bolon B, Ivy GO, Mak TW (2001) Deletion of Pten in mouse brain causes seizures, ataxia and defects in soma size resembling Lhermitte-Duclos disease. Nat Genet 29:396-403.

Bains M, Hall ED (2012) Antioxidant therapies in traumatic brain and spinal cord injury. Biochim Biophys Acta 1822:675-684.

Bergami M, Rimondini R, Santi S, Blum R, Götz M, Canossa M (2008) Deletion of TrkB in adult progenitors alters newborn neuron integration into hippocampal circuits and increases anxiety-like behavior. Proc Natl Acad Sci U S A 105:15570-15575.

Blaiss CA, Yu TS, Zhang G, Chen J, Dimchev G, Parada LF, Powell CM, Kernie SG (2011) Temporally specified genetic ablation of neurogenesis impairs cognitive recovery after traumatic brain injury. J Neurosci 31:4906-4916

Bruns J Jr, Hauser WA (2003) The epidemiology of traumatic brain injury: a review. Epilepsia 44 [Suppl 10]:2-10.

Buss RR, Sun W, Oppenheim RW (2006) Adaptive roles of programmed cell death during nervous system development. Annu Rev Neurosci 29:1-35.

Cai W, Rudolph JL, Harrison SM, Jin L, Frantz AL, Harrison DA, Andres DA (2011) An evolutionarily conserved Rit GTPase-p38 MAPK signaling pathway mediates oxidative stress resistance. Mol Biol Cell 22:3231-3241.

Colicelli J (2004) Human RAS superfamily proteins and related GTPases. Sci STKE 2004:RE13.

Gao X, Deng-Bryant Y, Cho W, Carrico KM, Hall ED, Chen J (2008) Selective death of newborn neurons in hippocampal dentate gyrus following moderate experimental traumatic brain injury. J Neurosci Res $86: 2258-2270$.

Gould E, Tanapat P (1997) Lesion-induced proliferation of neuronal progenitors in the dentate gyrus of the adult rat. Neuroscience 80:427-436.

Gould E, McEwen BS, Tanapat P, Galea LA, Fuchs E (1997) Neurogenesis in the dentate gyrus of the adult tree shrew is regulated by psychosocial stress and NMDA receptor activation. J Neurosci 17:2492-2498.

Jin K, Minami M, Lan JQ, Mao XO, Batteur S, Simon RP, Greenberg DA (2001) Neurogenesis in dentate subgranular zone and rostral subventricular zone after focal cerebral ischemia in the rat. Proc Natl Acad Sci U S A 98:4710-4715.

Kempermann G, Kuhn HG, Gage FH (1997) More hippocampal neurons in adult mice living in an enriched environment. Nature 386:493-495.

Kernie SG, Erwin TM, Parada LF (2001) Brain remodeling due to neuronal and astrocytic proliferation after controlled cortical injury in mice. J Neurosci Res 66:317-326.

Kuhn HG, Biebl M, Wilhelm D, Li M, Friedlander RM, Winkler J (2005) Increased generation of granule cells in adult Bcl-2-overexpressing mice: a role for cell death during continued hippocampal neurogenesis. Eur J Neurosci 22:1907-1915.

Kwon CH, Luikart BW, Powell CM, Zhou J, Matheny SA, Zhang W, Li Y, Baker SJ, Parada LF (2006) Pten regulates neuronal arborization and social interaction in mice. Neuron 50:377-388.

Lee CH, Della NG, Chew CE, Zack DJ (1996) Rin, a neuron-specific and calmodulin-binding small G-protein, and Rit define a novel subfamily of ras proteins. J Neurosci 16:6784-6794.

Lein PJ, Guo X, Shi GX, Moholt-Siebert M, Bruun D, Andres DA (2007) The novel GTPase Rit differentially regulates axonal and dendritic growth. J Neurosci 27:4725-4736.

Levin HS (1998) Cognitive function outcomes after traumatic brain injury. Curr Opin Neurol 11:643-646. 
Lewén A, Matz P, Chan PH (2000) Free radical pathways in CNS injury. J Neurotrauma 17:871-890.

Li Y, Luikart BW, Birnbaum S, Chen J, Kwon CH, Kernie SG, Bassel-Duby R, Parada LF (2008) TrkB regulates hippocampal neurogenesis and governs sensitivity to antidepressive treatment. Neuron 59:399-412.

Lin MT, Beal MF (2006) Mitochondrial dysfunction and oxidative stress in neurodegenerative diseases. Nature 443:787-795.

Liu Z, Fan Y, Won SJ, Neumann M, Hu D, Zhou L, Weinstein PR, Liu J (2007) Chronic treatment with minocycline preserves adult new neurons and reduces functional impairment after focal cerebral ischemia. Stroke $38: 146-152$.

Madathil SK, Evans HN, Saatman KE (2010) Temporal and regional changes in IGF-1/IGF-1R signaling in the mouse brain after traumatic brain injury. J Neurotrauma 27:95-107.

Magavi SS, Leavitt BR, Macklis JD (2000) Induction of neurogenesis in the neocortex of adult mice. Nature 405:951-955.

Mao Z, Bonni A, Xia F, Nadal-Vicens M, Greenberg ME (1999) Neuronal activity-dependent cell survival mediated by transcription factor MEF2. Science 286:785-790.

Mattson MP (2008) Glutamate and neurotrophic factors in neuronal plasticity and disease. Ann N Y Acad Sci 1144:97-112.

Meng Y, Xiong Y, Mahmood A, Zhang Y, Qu C, Chopp M (2011) Dosedependent neurorestorative effects of delayed treatment of traumatic brain injury with recombinant human erythropoietin in rats. J Neurosurg 115:550-560.

Ming GL, Song H (2011) Adult neurogenesis in the mammalian brain: significant answers and significant questions. Neuron 70:687-702.

Minichiello L, Klein R (1996) TrkB and TrkC neurotrophin receptors cooperate in promoting survival of hippocampal and cerebellar granule neurons. Genes Dev 10:2849-2858.

Mu Y, Lee SW, Gage FH (2010) Signaling in adult neurogenesis. Curr Opin Neurobiol 20:416-423.

Petreanu L, Alvarez-Buylla A (2002) Maturation and death of adultborn olfactory bulb granule neurons: role of olfaction. J Neurosci 22:6106-6113.

Pleasant JM, Carlson SW, Mao H, Scheff SW, Yang KH, Saatman KE (2011) Rate of neurodegeneration in the mouse controlled cortical impact model is influenced by impactor tip shape: implications for mechanistic and therapeutic studies. J Neurotrauma 28:2245-2262.

Povlishock JT, Katz DI (2005) Update of neuropathology and neurological recovery after traumatic brain injury. J Head Trauma Rehabil 20:76-94.

Reichardt LF (2006) Neurotrophin-regulated signalling pathways. Philos Trans R Soc Lond B Biol Sci 361:1545-1564.

Rola R, Mizumatsu S, Otsuka S, Morhardt DR, Noble-Haeusslein LJ, Fishman K, Potts MB, Fike JR (2006) Alterations in hippocampal neurogenesis following traumatic brain injury in mice. Exp Neurol 202:189-199.

Rudolph JL, Shi GX, Erdogan E, Fields AP, Andres DA (2007) Rit mutants confirm role of MEK/ERK signaling in neuronal differentiation and reveal novel Par6 interaction. Biochim Biophys Acta 1773:1793-1800.
Schäbitz WR, Steigleder T, Cooper-Kuhn CM, Schwab S, Sommer C, Schneider A, Kuhn HG (2007) Intravenous brain-derived neurotrophic factor enhances poststroke sensorimotor recovery and stimulates neurogenesis. Stroke 38:2165-2172.

Shi GX, Andres DA (2005) Rit contributes to nerve growth factor-induced neuronal differentiation via activation of B-Raf-extracellular signalregulated kinase and p38 mitogen-activated protein kinase cascades. Mol Cell Biol 25:830-846.

Shi GX, Jin L, Andres DA (2011) A rit GTPase-p38 mitogen-activated protein kinase survival pathway confers resistance to cellular stress. Mol Cell Biol 31:1938-1948.

Sholl DA (1953) Dendritic organization in the neurons of the visual and motor cortices of the cat. J Anat 87:387-406.

Sierra A, Encinas JM, Deudero JJ, Chancey JH, Enikolopov G, OverstreetWadiche LS, Tsirka SE, Maletic-Savatic M (2010) Microglia shape adult hippocampal neurogenesis through apoptosis-coupled phagocytosis. Cell Stem Cell 7:483-495.

Spencer ML, Shao H, Tucker HM, Andres DA (2002a) Nerve growth factor-dependent activation of the small GTPase Rin. J Biol Chem 277:17605-17615.

Spencer ML, Shao H, Andres DA (2002b) Induction of neurite extension and survival in pheochromocytoma cells by the Rit GTPase. J Biol Chem 277:20160-20168.

Sun W, Winseck A, Vinsant S, Park OH, Kim H, Oppenheim RW (2004) Programmed cell death of adult-generated hippocampal neurons is mediated by the proapoptotic gene Bax. J Neurosci 24:11205-11213.

Tashiro A, Sandler VM, Toni N, Zhao C, Gage FH (2006) NMDA-receptormediated, cell-specific integration of new neurons in adult dentate gyrus. Nature 442:929-933.

Thornton TM, Pedraza-Alva G, Deng B, Wood CD, Aronshtam A, Clements JL, Sabio G, Davis RJ, Matthews DE, Doble B, Rincon M (2008) Phosphorylation by p38 MAPK as an alternative pathway for GSK3beta inactivation. Science 320:667-670.

Wagner EF, Nebreda AR (2009) Signal integration by JNK and p38 MAPK pathways in cancer development. Nat Rev Cancer 9:537-549.

Weinstein DE, Burrola P, Kilpatrick TJ (1996) Increased proliferation of precursor cells in the adult rat brain after targeted lesioning. Brain Res 743:11-16.

Wes PD, Yu M, Montell C (1996) RIC, a calmodulin-binding Ras-like GTPase. EMBO J 15:5839-5848.

Young D, Lawlor PA, Leone P, Dragunow M, During MJ (1999) Environmental enrichment inhibits spontaneous apoptosis, prevents seizures and is neuroprotective. Nat Med 5:448-453.

Zhang X, Chen Y, Ikonomovic MD, Nathaniel PD, Kochanek PM, Marion DW, DeKosky ST, Jenkins LW, Clark RS (2006) Increased phosphorylation of protein kinase B and related substrates after traumatic brain injury in humans and rats. J Cereb Blood Flow Metab 26:915-926.

Zhao C, Deng W, Gage FH (2008) Mechanisms and functional implications of adult neurogenesis. Cell 132:645-660. 